\title{
Intraoperative graft flow assessment for myocardial surgical revascularization
}

\author{
Mateo Marin-Cuartas, Piroze M. Davierwala \\ University Department of Cardiac Surgery, Leipzig Heart Center, Leipzig 04289, Germany. \\ Correspondence to: Dr. Piroze M. Davierwala, University Department of Cardiac Surgery, Leipzig Heart Center, \\ Struempellstrasse 39, Leipzig 04289, Germany. E-mail: pirarm@hotmail.com
}

How to cite this article: Marin-Cuartas M, Davierwala PM. Intraoperative graft flow assessment for myocardial surgical revascularization. Vessel Plus 2021;5:32. https://dx.doi.org/10.20517/2574-1209.2021.32

Received: 19 Feb 2021 First Decision: 30 Mar 2021 Revised: 16 Apr 2021 Accepted: 18 May 2021 Published: 23 Jun 2021

Academic Editor: Cristiano Spadaccio Copy Editor: Xi-Jun Chen Production Editor: Xi-Jun Chen

\begin{abstract}
Intraoperative graft assessment should be considered a vital step during surgical myocardial revascularization that is performed following completion of grafting. It provides the surgeon a tool to assess graft flow and quality. Hence, it reduces graft failure rates related to avoidable or correctable technical errors, leading to improved early and late postoperative outcomes. Additionally, modern intraoperative functional coronary flow tests facilitate decisionmaking regarding the indication for revascularization of a particular vessel based on the functional significance and degree of ischemia induced by a lesion in that coronary artery. A wider implementation of intraoperative graft assessment modalities has the potential to improve graft patency and outcomes following myocardial revascularization. However, further research in the field is required before it becomes the standard of care during coronary artery bypass graft surgery. This article provides a general review of strategies and methods of coronary artery graft flow assessment, focusing on their availability and feasibility as well as strengths and limitations.
\end{abstract}

Keywords: CABG, intraoperative graft flow assessment, transit-time flow measurement, high-resolution epicardial ultrasonography, fractional flow reserve

\section{INTRODUCTION}

Estimated mid- to long-term graft dysfunction after coronary artery bypass grafting (CABG) ranges from $5 \%$ for internal thoracic artery grafts to $25 \%$ for saphenous vein grafts ${ }^{[1]}$. It has been recognized as one of the most significant risk factors for postoperative myocardial infarction and hemodynamic instability. 
Intraoperative graft assessment is now a routine step after surgical myocardial revascularization, at least in certain institutes, since it provides the surgeon a tool to verify graft flows and quality. Surgeons, who routinely use intraoperative transit-time flow measurement (TTFM), report that intraoperative revision of coronary bypass grafts occurs in approximately $2 \%-4 \%$ of the grafts ${ }^{[2]}$. Hence, it reduces graft failure rates related to avoidable or correctable technical errors, leading to improved early and late postoperative outcomes ${ }^{[3-5]}$. However, due to heterogeneous data from diverse studies, drawing uniform conclusions and definitive recommendations is challenging ${ }^{[5]}$. The use of dissimilar cut-off levels representing adequate graft flows, different techniques of CABG (off- or on-pump), varied grafting strategies (single vs. sequential/composite grafts) and type of grafts used (arterial $v s$. venous), different time-points of measurement of graft flows during the operation with respect to weaning from cardiopulmonary bypass and administration of protamine, the site of measurement on the graft (proximal or distal), and the type of modality or combination of modalities used for assessment in observational studies published so far have resulted in the lack of robustness in the evidence available in the literature. Further research and more robust evidence are required to improve the class of recommendation for intraoperative graft flow assessment. In addition to the clinical importance and benefit of intraoperative graft assessment for the patient, it also provides an educational perspective by facilitating surgeons in improving their skills in addition to maintaining the safety of procedures performed by young surgeons in training. An ideal intraoperative method to verify adequate flows in coronary grafts and vessels should be easy to handle, not time-consuming, non-invasive, and easily interpretable, reproducible, and accessible ${ }^{[6]}$. This article provides a general review of strategies and methods of coronary artery graft assessment, focusing on their availability and feasibility as well as strengths and limitations. The key points of this review are summarized in Table 1.

\section{HISTORICAL ASPECTS OF INTRAOPERATIVE GRAFT ASSESSMENT}

The necessity to assess the graft function was recognized in the early days following the inception of CABG surgery. In 1971, electromagnetic flow measurement was described by Grondin et al. ${ }^{[7]}$ as an effective intraoperative method to verify accurate blood flow of saphenous vein grafts. They reported that $94.4 \%$ of the grafts with an intraoperative mean graft flow $(\mathrm{MGF})<48 \mathrm{~mL} / \mathrm{min}$ were occluded at one-year follow-up angiography. However, the major drawback of this technique was that the measured values were strongly influenced by many different variables such as hematocrit, vessel diameter, device calibration issues, and motion artifacts. The introduction of epicardial high-resolution ultrasonography (HR-US) in the 1980s and TTFM in the 1990s, in addition to the widespread use of off-pump CABG, renewed the interest in intraoperative graft assessment after more than 30 years of development and improvement in various intraoperative flow assessment methods ${ }^{[8]}$. HR-US, as it is known nowadays, has been used in standard fashion since it was introduced in 2012. Furthermore, continuous technological advances in this field have led to significant improvements in the intraoperative graft function assessment methods, thereby allowing the devices to become affordable and more available. Nonetheless, there is still some reluctance on the part of surgeons in using this technology. According to the report by Tan et al..$^{[9]}$, the use of TTFM does not exceed $20 \%$ of CABG cases.

Moreover, a gradual shift in approach to revascularization is occurring in recent times, which has led to a change in concept with respect to indications for revascularization. Randomized controlled trials have demonstrated that percutaneous coronary intervention (PCI) based on functional assessment of a lesion is associated with better outcomes than conventional anatomy/angiography-based evaluation ${ }^{[10-14]}$. It can be determined by means of fractional flow reserve (FFR) analysis. The same concept has recently been applied to surgical revascularization as well, but with varying results ${ }^{[1,1,16]}$. Near-infrared fluorescence (NIRF) angiography with fluorophore indocyanine green (ICG) dye is used to perform intraoperative $\mathrm{FFR}^{[17-20]}$. This new technology enables modern surgical revascularization based on dynamic functional parameters and not 
- Intraoperative coronary flow assessment leads to intraoperative revision of anastomoses in approximately $2 \%$ - $4 \%$ of bypass grafts. Minor graft alterations occur even more frequently

- Intraoperative coronary flow assessment can facilitate residents in training to be better surgeons

- The combination of TTFM and HR-US improves the performance of intraoperative coronary graft assessment, leading to improved outcomes and patient safety

- Intraoperative coronary flow assessment should be considered as part of "best practices" in coronary surgery and is now recommended by current management guidelines

- Functional coronary graft assessment methods are breaking old paradigms in conventional coronary surgery and may change our surgical strategies and treatment approaches in the near future

TTFM: Transit-time flow measurement; HR-US: high-resolution ultrasonography.

solely on anatomic findings.

\section{EPICARDIAL HIGH-RESOLUTION ULTRASONOGRAPHY}

HR-US is a morphological imaging test for graft and native vessel evaluation based on epicardial ultrasonography [Figure 1A]. Sahn et al. ${ }^{[21]}$ reported the first clinical use of HR-US in 1982. They utilized HR-US intraoperatively, first in sheep, to assess the coronary vessels and thereafter in patients with normal coronary angiograms undergoing non-coronary surgery (e.g., valvular surgery) as well as in those undergoing $\mathrm{CABG}$ for intraoperative assessment of known atherosclerotic lesions to locate the appropriate site for performing the anastomosis. The observations obtained by intraoperative HR-US correlate very well with the preoperative angiographic findings (R-value of 0.91). In 1986, Hiratzka et al. ${ }^{[22]}$ reported the use of HR-US for intraoperative assessment of coronary graft anastomoses. The use of epicardial HR-US for the measurement of wall thickness and vessel lumen diameter of coronary arteries was validated in 1986 by an animal study published by McPherson et al. ${ }^{[23]}$. A good correlation was found between images obtained by HR-US and those observed on histology, leading to the conclusion that epicardial HR-US is a useful tool for intraoperative coronary artery assessment. Since then, several improvements have been made in this technique such as the development of smaller and sterilizable echo probes with a wider frequency range from 8 to $18 \mathrm{MHz}$, which has led to an increasing implementation of the epicardial HR-US during CABG. It has simplified and optimized the evaluation of native coronary arteries and grafts during cardiac surgery. Moreover, with the addition of doppler and color flow mapping, assessment of the extent of atherosclerotic plaque as well as the degree of lumen stenosis and flow acceleration can be easily performed ${ }^{[24]}$. In 2012 , Medistim ASA introduced the VeriQC machine at the annual meeting of the European Association of Cardio-Thoracic Surgery in Barcelona. It was the first device that incorporated TTFM with HR-US using a re-sterilizable HR-US probe ${ }^{[8]}$. Several manufacturers now offer different models of HR-US probes and devices. Given the improved reliability, reproducibility, and availability of this method, many cardiac surgery groups around the world routinely use HR-US for intraoperative assessment of native coronary $\operatorname{arteries}^{[25]}$.

An additional benefit of HR-US is the localization of coronary arteries with an intramyocardial course. Moreover, HR-US is of great use in evaluating the quality of vessels with chronic total occlusion (CTO) and thereby their feasibility and suitability for grafting, since standard coronary angiography frequently provides limited information in such cases. Additionally, HR-US is also beneficial during off-pump CABG to accurately choose the size of the shunt that would best fit the vessel during anastomosis, because it facilitates the measurement of the luminal diameter of the native target coronary following stabilization.

\section{Procedural aspects for HR-US}

Modern HR-US probes are small and emit ultrasound frequencies from 8 to $18 \mathrm{MHz}^{[25]}$. During the measurement, the probe should be held between the index and middle fingers. For evaluation of the left 

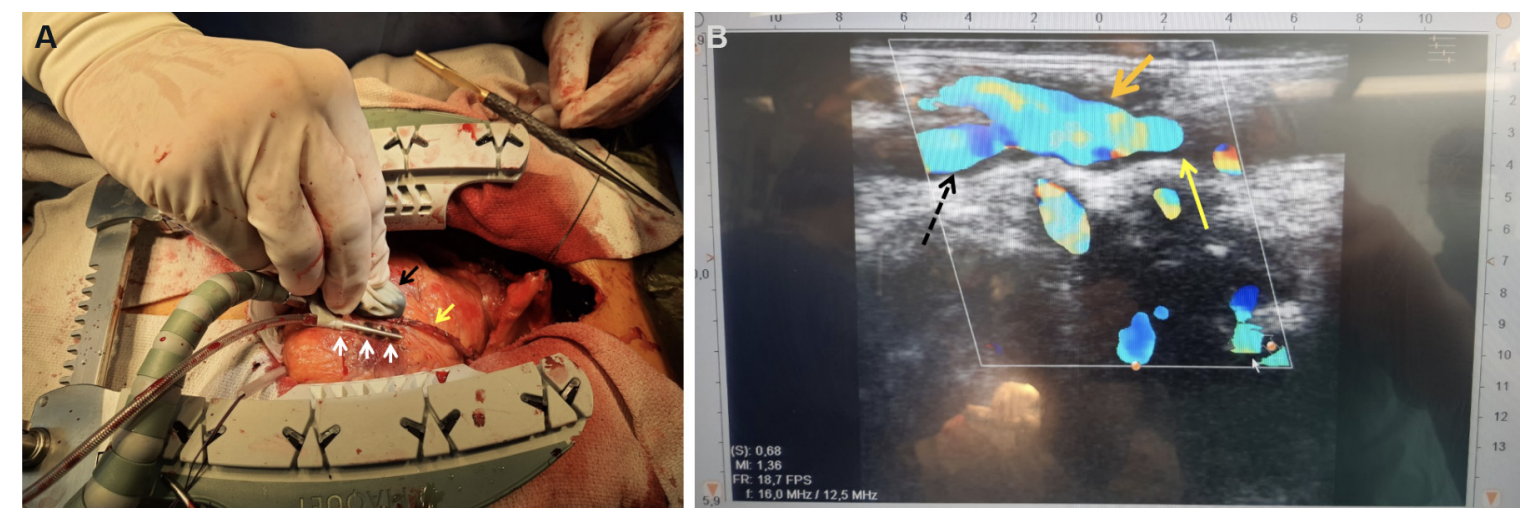

Figure 1. Intraoperative setup for epicardial high-resolution ultrasonography. The black arrow shows the epicardial ultrasonography probe; the white arrows show the foot pods of the stabilizer, where the distal anastomosis must be stabilized during high-resolution ultrasonography to reduce image motion artifacts; and the yellow arrow shows the left internal thoracic artery graft to the left anterior descendent coronary artery (A). Image obtained through intraoperative epicardial high-resolution ultrasonography with doppler flow measurement. The orange arrow shows the anastomosis; the yellow arrow depicts flows in native vessel distal to the anastomosis; and the black hatched arrow depicts flows in the native vessel proximal to the anastomosis (B).

coronary system, the left main can be easily found by scanning from its origin by passing the probe between the left atrium and the pulmonary artery until the transverse sinus is reached. Once the top of the left main is identified, the scan can continue down to the bifurcation, continuing to the proximal segment of the left anterior descending artery (LAD) and to the left circumflex coronary artery (LCx). When sliding the probe distally into the bifurcation of the left main, the LAD can be seen on the right and the LCx on the left in the short axis view, and, in the presence of a ramus intermedius, it will appear between the LAD and $\mathrm{LCx}^{[25]}$. For evaluation of the right coronary system, the probe can be positioned at the origin of the right coronary artery, starting from the aorta and moving down towards the right atrio-ventricular groove until reaching the acute margin of the heart just above the crux cordis ${ }^{[25]}$.

Both proximal and distal anastomoses should be scanned in long and cross-sectional views with 2D mode and color flow doppler. During off-pump CABG, the distal anastomosis should be scanned after stabilization of the vessel in order to avoid motion artifacts, thereby improving imaging quality [Figure $1 \mathrm{~B}]^{[25]}$. During on-pump CABG, the anastomosis between a free-graft and the native vessel can be scanned by delivering cardioplegia through the graft, whereas, in the case of an in situ arterial conduit, temporary declamping of the graft allows adequate imaging of the anastomosis ${ }^{[25]}$. Additionally, sterile gel can be applied on the graft or the pericardial cavity can be filled with warm physiological saline solution to optimize acoustic coupling. Excessive compression of the coronary vessel with the HR-US probe must be avoided to prevent over- or underestimation of the degree of stenosis.

\section{TRANSIT-TIME FLOW MEASUREMENT}

TTFM is a functional graft flow test which is based on the Doppler principle. It calculates blood flow from the difference in the arrival time of ultrasound waves from the upstream and downstream transmission ${ }^{[26]}$. Piezoelectric crystals in the probe emit ultrasound waves, and a reflector on the opposite side of the vessel reflects these emitted waves, which are then transmitted back to the piezoelectric crystals in the probe [Figure $2 \mathrm{~A}$ and $\mathrm{B}$ ]. The time-delay in the transmission of waves back to the probe is proportional to blood flow through the vesse ${ }^{[6,26]}$. TTFM, compared to the electromagnetic flow meter, is not influenced by hematocrit or vessel caliber and does not need any previous calibration ${ }^{[27]}$. The main parameters reported by TTFM are pulsatility index (PI), MGF, diastolic filling (DF), and backward flow (BF). PI is calculated by the difference between the peak flow and minimum flow divided by MGF. DF is the amount of blood flow in 

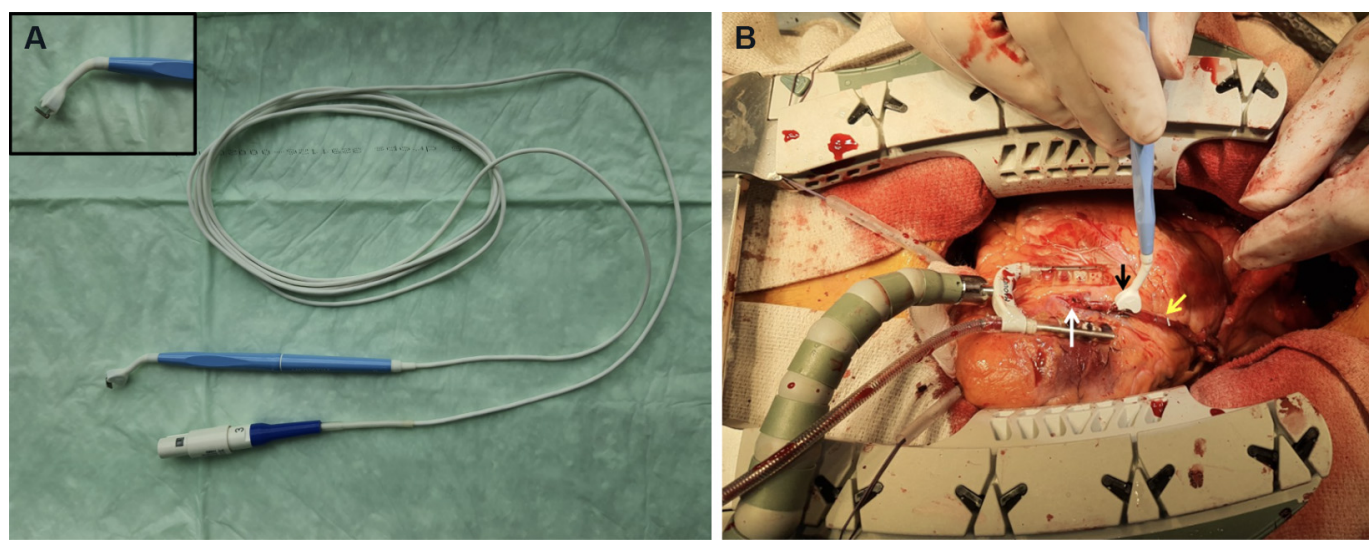

Figure 2. Transit-time flow measurement probe (A). Intraoperative transit-time flow measurement during off-pump coronary artery bypass grafting. The white arrow shows the distal anastomosis; the black arrow shows the transit-time flow measurement probe engulfing the left internal thoracic artery; and the yellow arrow shows the left internal thoracic artery graft (B).

the coronary arteries during diastole. BF accounts for competitive flow, which is the retrograde flow of blood from the native coronary artery back into the graft. It corresponds to the percentage of the flow curve area that lies below the zero line, and it is expressed as a percentage.

TTFM has been provided a Class IIa B recommendation in the current European Society of Cardiology and Cardiothoracic Surgery guidelines for myocardial revascularization ${ }^{[3,4]}$. Its intraoperative use for graft flow analysis during CABG has dramatically increased, since it is less invasive, highly reproducible, and less time-consuming compared to all graft flow assessment methods. Although there are no randomized controlled trials (RCT) demonstrating a clear association between TTFM and angiographic patency, observational studies have shown a correlation between various TTFM measurements and graft function. A retrospective, single-center study published by Di Giammarco et al. ${ }^{[28]}$ and Kim et al. ${ }^{[29]}$ including 227 arterial grafts and 77 saphenous grafts in 157 patients reported a correlation between the combination of $\mathrm{MGF} \leq 15 \mathrm{~mL} / \mathrm{min}, \mathrm{PI} \geq 3.0$, and $\% \mathrm{BF} \geq 3 \%$ and graft failure at an angiographic follow-up of $6.7 \pm 4.8$ months for both arterial and saphenous grafts. Tokuda et al. ${ }^{[30]}$ assessed 104 grafts with follow-up angiography performed at 1-4 postoperative years and found that low MGF (i.e., 15 and $20 \mathrm{~mL} / \mathrm{min}$ for left and right coronary arteries, respectively) was an independent predictor of graft failure. Similarly, one prospective angiography-controlled study published by Jokinen et al..$^{[31]}$ and Kieser et al.$^{[32]}$ including 204 grafts observed that PI $>3$ was the best independent predictor of graft failure at 6 months. Moreover, in this study, TTFM parameters were not associated with postoperative serum cardiac enzyme levels and did not correlate with the occurrence of death, myocardial infarction, or stroke. As a general rule, the following values are generally accepted for adequate bypass graft function: (1) flow $>15 \mathrm{~mL} / \mathrm{min}$; (2) PI $<5.0$ is acceptable, but $<3.0$ is ideal; and (3) DF $=60 \%-80 \%$ for grafts to the left coronary tree and $45 \%-55 \%$ for the right coronary circulation ${ }^{[8]}$. Table 2 shows several reported cut-offs for TTFM parameters according to the experience of different groups ${ }^{[29-32]}$.

Cut-off values for MGF must be used with caution since higher levels could markedly lower the specificity of TTFM. This would result in an increased number of false positive results (i.e., normally functioning grafts diagnosed to have faulty anastomoses or graft problems). Additionally, vessels with poor distal run-off usually demonstrate a poor flow curve with low MGFs and high PIs, which may be suggestive of a faulty anastomosis. Therefore, the quality of the native target vessel should always be taken into consideration while interpreting the TTFM measurements. Furthermore, TTFM used in isolation may not be accurate enough, since $10 \%-15 \%$ of grafts assessed reveal ambiguous or inconclusive results ${ }^{[8]}$. Hence, the combined 
Table 2. Cut-off values for different TTFM parameters reported in different studies

\begin{tabular}{llll}
\hline Ref. (year) & Cut-off values for dysfunctional graft & Sensitivity (\%) & Specificity (\%) \\
\hline Kim et al. ${ }^{[28]}$ (2005) & $\mathrm{MGF}<15 \mathrm{~mL} / \mathrm{min} ; \mathrm{Pl}>3$ (LCA)/PI > 5 (RCA) & 96 & 77 \\
Di Giammarco et al. ${ }^{[29]}$ (2006) & $\mathrm{MGF} \leq 15 \mathrm{~mL} / \mathrm{min} ; \mathrm{PI} \geq 3$ & 94 & 61 \\
Tokuda et al. $^{[30]}$ (2007) & $\mathrm{MGF} \leq 15 \mathrm{~mL} / \mathrm{min} ; \mathrm{PI} \geq 5.1$ (LCA) MGF $\leq 20 \mathrm{~mL} / \mathrm{min} ; \mathrm{PI} \geq 4.7$ (RCA) & 26 & 98 \\
& & 60 & 98 \\
Kieser et al. ${ }^{[31]}$ (2010) & $\mathrm{Pl}>5$ & - & - \\
\hline
\end{tabular}

Modified from Di Giammarco ${ }^{[25]}$. MGF: Mean graft flow; PI: pulsatility index; LCA: left coronary artery; RCA: right coronary artery.

use of functional graft assessment with TTFM and morphological assessment with HR-US increases the diagnostic accuracy of the intraoperative graft evaluation by not only facilitating flow measurement, but also imaging of the anastomosis and the graft itself ${ }^{[33]}$. Taggart et al. ${ }^{[34]}$ observed that the use of TTFM in combination with HR-US in patients undergoing CABG resulted in alteration of the initial surgical plan and/or graft revisions in $25 \%$ of patients, leading to low operative mortality (0.6\%) and lower rates of serious in-hospital complications (cerebrovascular events: 1.0\%; myocardial infarction: 0.3\%).

In addition to the above-mentioned parameters, graft flow reserve is also an important aspect of functional assessment of coronary grafts. It can be assessed by means of a dobutamine test. It predicts long-term durability of grafts, because it can unmask suboptimal flow patterns that are not observed under rest conditions ${ }^{[35]}$. An intravenous bolus of $20 \mu \mathrm{g} / \mathrm{kg}$ of dobutamine is administered and the TTFM measurements are then acquired. An intraoperative graft assessment chart is proposed in Figure 3, based on the publication by Di Giammarco et al. ${ }^{[6]}$.

Most TTFM variables, including MGF, are strongly affected by changes in hemodynamics and the degree of stenosis in coronary vessels, which are assessed by FFR. To counteract these effects on the assessment of graft function, TTFM devices can also run an algorithm called "fast Fourier transform" (FFT) ratio, which is not influenced by such dynamic factors ${ }^{[36]}$. Hence, FFT analysis of the TTFM measurements may be recommended for grafts to vessels with moderate stenoses and a FFR $>0.75$.

\section{Procedural aspects for TTFM}

The device displays a flow curve with systolic and diastolic components [Figure 4]. Accurate interpretation of the different flow patterns allows identification and correction of technical errors prior to chest closure $^{[37]}$. The normal flow pattern in the left coronary system depicts a diastolic predominance with low systolic peaks. Contrarily, the normal pattern in the right coronary system has a systolic predominance with high systolic peaks ${ }^{[6]}$. Additionally, the flow pattern can slightly change according to the site of graft measurement: when the probe is close to the proximal anastomosis, the pattern is mainly systolic. If the probe is placed in the middle segment of the graft, the curve is well balanced with similar systolic and diastolic components. When the probe is closer to distal anastomosis, the pattern turns more diastolic since the measured flow pattern resembles the intracoronary flow pattern with low graft impedance ${ }^{[6]}$. Armless probes are now available to facilitate graft flow measurements in minimally invasive coronary surgery [Figure 5].

Measurements being altered by technical errors must be recognized. Typically, low MGF $(<15 \mathrm{~mL} / \mathrm{min})$, high PI (>3), and low DF are suggestive of a faulty anastomosis ${ }^{[6]}$. To obtain reliable values, compression of the graft with too small a probe must be avoided. Additionally, good acoustic coupling can be obtained by using sterile ultrasound gel. The probe should be placed as close as possible to the distal anastomosis and graft kinking must be prevented. Enough time should be taken to perform every flow assessment 


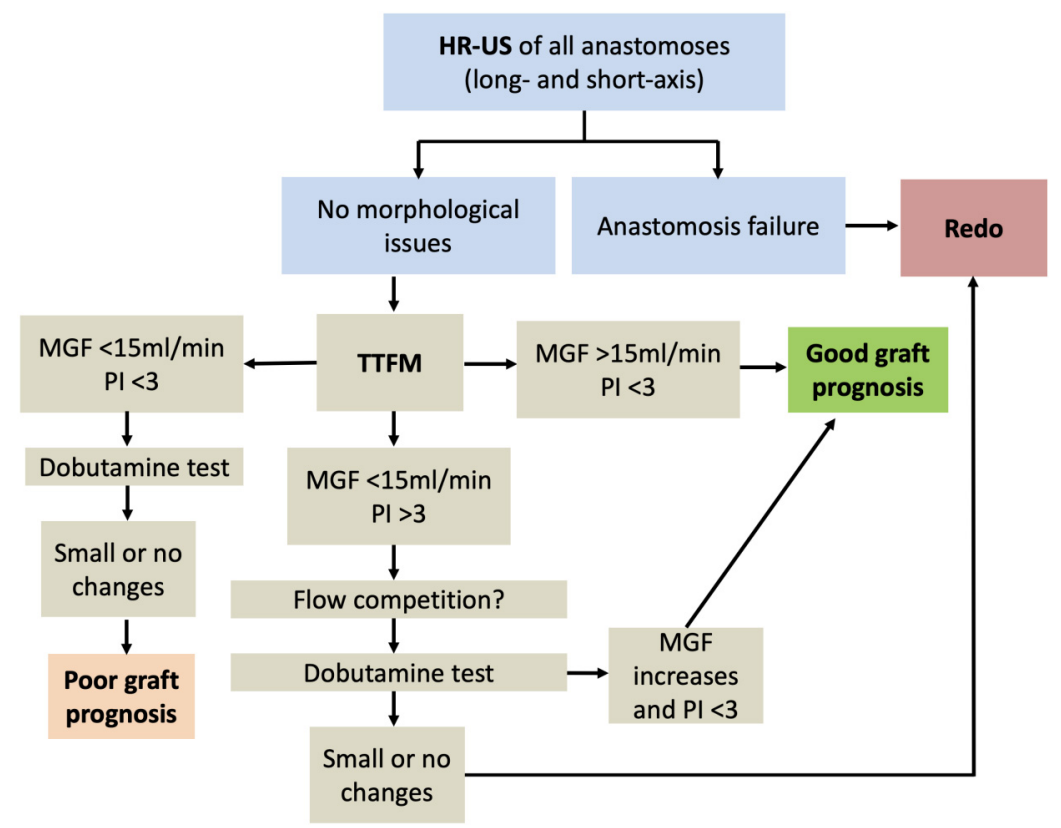

Figure 3. Intraoperative graft assessment flow chart (modified from Di Giammarco et al. ${ }^{[6]}$ ). HR-US: Epicardial high-resolution ultrasonography; TTFM: transit-time flow measurement; MGF: mean graft flow; PI: pulsatility index.

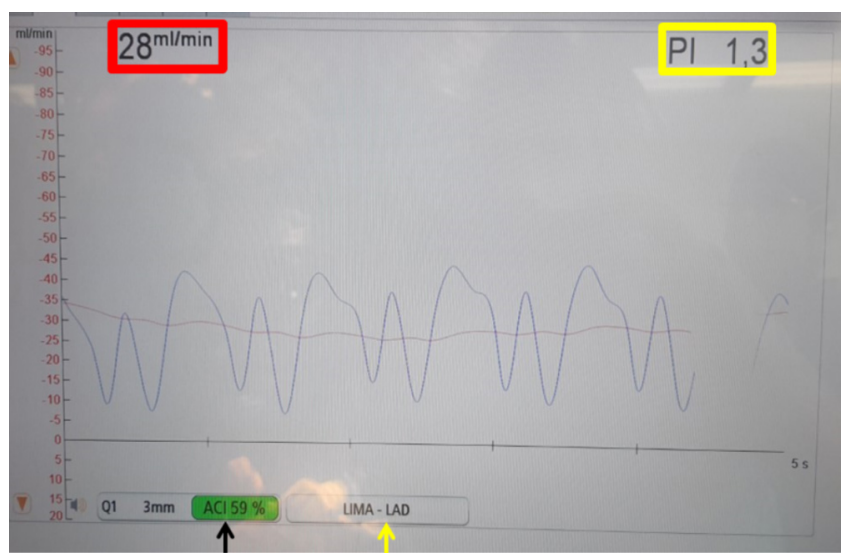

Figure 4. Intraoperative transit-time flow measurement of a left internal thoracic artery graft (LITA) to the left anterior descendent coronary artery (yellow arrow). The $x$-axis of the graph represents time in seconds and the $y$-axis represents flow in $\mathrm{mL} / \mathrm{min}$. The red box depicts the mean flow through the graft (LITA), which in this case is $28 \mathrm{~mL} / \mathrm{min}$. The yellow box depicts the pulsatility index, which in this case is 1.3. The acoustic coupling index ( $\mathrm{ACl}$ ) (black arrow) is 59\% (if the background of this number is green, it portrays adequate contact between the probe and the graft for a correct transit-time flow measurement).

confirming that the device indicates complete stabilization before recording the values. The device should ideally be coupled with the patient's ECG and blood pressure in order to obtain reliable measurements, especially for the DF measurement and analysis. Two TTFM measurements should ideally be performed, the first one after the completion of the anastomoses with the heart in normal position, following release of the aortic cross-clamp and weaning from cardiopulmonary bypass, and another after heparin reversal prior to chest closure ${ }^{[25]}$.

\section{INTRAOPERATIVE FRACTIONAL FLOW RESERVE}

FFR is a physiological assessment of coronary and graft flow that links the anatomic and functional aspects 


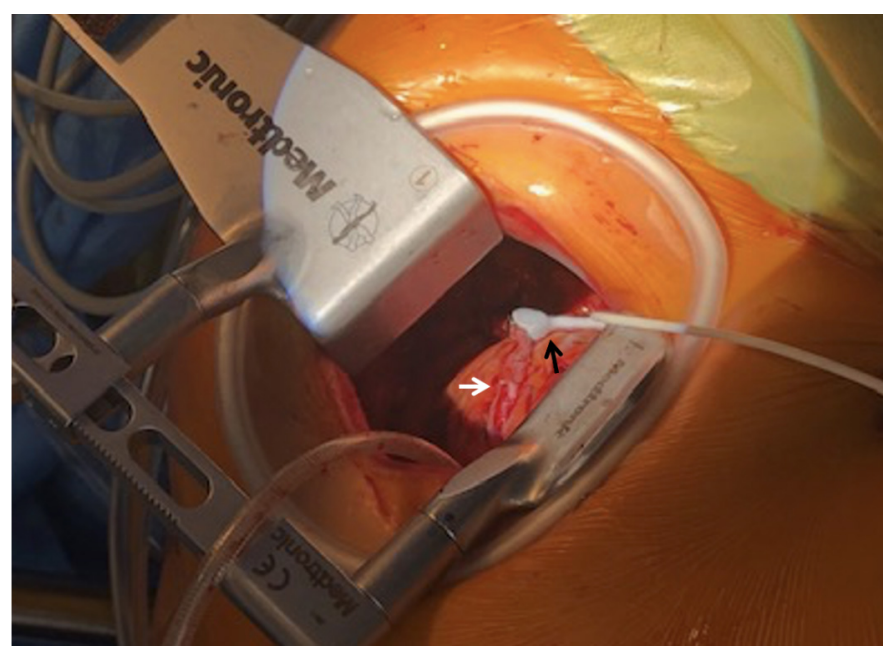

Figure 5. An armless probe (black arrow) can be used to facilitate transit-time flow measurement in minimally invasive coronary surgery. The left internal thoracic artery is being assessed. The white arrow shows the anastomosis between the left internal thoracic artery and the left anterior descending coronary artery.

of coronary lesions to evaluate the degree of ischemia induced by a specific diseased target vessel ${ }^{[38]}$. The use of FFR as part of the preoperative coronary angiography to establish the indication for CABG is significantly increasing ${ }^{[13,39]}$. This physiology-based evaluation of coronary artery disease is a revolution in both PCI and CABG. It is well-known that a significant degree (>10\%) of myocardial ischemia is required for revascularization strategies to have clinical benefit ${ }^{[40]}$. In the Fractional Flow Reserve Versus Angiography for Multivessel Disease (FAME) trial ${ }^{[14]}, 20 \%$ of the anatomic lesions with $71 \%-90 \%$ stenosis and $60 \%$ of lesions with $51 \%-70 \%$ had no functional impact. Moreover, a significant number of patients with three-vessel anatomic disease were reclassified as having one- or two-vessel functional disease in the FAME 2 trial ${ }^{[14]}$. Similarly, Sant'Anna et al. ${ }^{[41]}$ demonstrated that, if FFR is used, the incidence of significant three-, two- and one-vessel angiographic coronary disease drops from $27 \%$ to $9 \%, 43 \%$ to $17 \%$, and $30 \%$ to $60 \%$, respectively. This could potentially simplify the decision-making process about the revascularization strategy. FFR-guided coronary artery bypass graft surgery was associated with a lower number of anastomoses $(2-3$ vs. $2-4 ; P<0.001)$ and a lower rate of on-pump CABG compared with angiographyguided CABG $(49 \% v s .69 \% ; P<0.001)$ in a RCT performed by Toth et al. ${ }^{[42]}$. Additionally, major adverse cardiovascular event rates at the 36-month follow-up mark were similar between both groups (12\% vs. $11 \%$; $\mathrm{HR}=1.030 ; 95 \% \mathrm{CI}: 0.627-1.692 ; P=0.908)$. and FFR-guided CABG was associated with lower rates of recurrent/residual angina (CCS Classes II-IV, $31 \%$ vs. 47\%; $P<0.001$ ). The impact of preoperative fractional flow reserve on arterial bypass graft anastomotic function (IMPAG trial) ${ }^{[16]}$, which was a prospective doubleblind study that assessed the influence of preoperative FFR measurement of coronary lesions on anastomotic patency 6 months after CABG using a multi-arterial grafting strategy, revealed significantly higher patency rates in patients revascularized as per preoperative FFR $(\mathrm{P}<0.001)$. An FFR cut-off of $\leq 0.78$ was associated with an anastomotic occlusion rate of $3 \%$. Similarly, the FAME trials also used a cut-off value of $\leq 0.8^{[13,14]}$.

The use of FFR has expanded with its use being extended from the preoperative angiography suite to the operation room. In their study based on intraoperative FFR with NIRF, Ferguson et al ${ }^{[19]}$ observed that a relevant number of angiographically patent bypass grafts did not have any impact on regional myocardial perfusion (24\% of arterial and $22 \%$ of saphenous vein grafts showed no changes in regional myocardial perfusion in response to bypass grafting). Of the $165 \mathrm{in} \mathrm{situ} \mathrm{ITA} \mathrm{grafts} \mathrm{to} \mathrm{the} \mathrm{left} \mathrm{anterior} \mathrm{descending} \mathrm{artery}$ (> 70\% stenosis), 40 showed no change in regional myocardial perfusion, of which 32 demonstrated 
competitive flow on imaging ${ }^{[19]}$. This confirmed that anatomic lesions in those target coronary vessels were functionally irrelevant and were associated with competitive graft flow. Hence, intraoperative NIRF coronarography opens the doors to an emerging FFR-guided CABG era, which is based more on dynamic functional imaging than on static anatomical lesion description.

NIRF coronarography uses a nontoxic fluorophore called ICG, which is administered as an intravenous bolus injection ${ }^{[43,4]}$. ICG has a half-life of approximately $90 \mathrm{~s}$. It binds to endothelial cells and circulating proteins and has hepatic metabolism and renal excretion ${ }^{[19]}$. The ICG is excited by a low-energy nearinfrared (NIR) laser, and then the fluorescent images are collected with a high-speed camera ${ }^{[19]}$. NIR is beyond the visible wavelength spectrum. Therefore, the standard image presentation is a gray scale image or alternatively a warm/cold color image. This graphical representation facilitates the visual differentiation of the different levels of perfusion according to the levels of fluorescence. Since no radiation is involved, multiple ICG injections and image sets can be safely obtained. The fluorescence intensity is proportional to the concentration of ICG and the circulating blood volume. Moreover, the tissue fluorescence intensity is directly proportional to the myocardial blood flow and perfusion. Hence, the degree of variation in tissue fluorescence intensity is an indicator of the degree of change in myocardial perfusion ${ }^{[19]}$ and the real functional consequence of coronary stenosis.

Intraoperative FFR with NIRF is performed under a "resting" state with stable heart rate, blood pressure, and coronary autoregulation. It provides a comparison of the pre- and post-grafting images (i.e., direct comparison of the difference in native flow of the coronary arteries $v s$. the flow in the coronary arteries and the bypass graft, as well as the resulting effect on myocardial perfusion). Therefore, this technique does not provide evaluation of stress-induced myocardial perfusion and could therefore underestimate the functional relevance of some borderline lesions. The long-term benefits on graft durability after NIRF FFR-guided CABG are still unclear. Nonetheless, this technology opens a window to a better physiologic understanding of what happens to the coronary circulation after bypass grafting. It can provide information about possible causes of intermediate to late graft failure. Nevertheless, the results of the available studies must be viewed with caution and more research is required in this field, because one could interpret from current FFR studies that the strategy adopted for CABG based on anatomic assessment of lesions on coronary angiography during the last 50 years has been flawed, even if the outcomes of patients with coronary artery disease have dramatically improved with the routine implementation of $\mathrm{CABG}^{[1,11,45]}$.

\section{FUTURE PERSPECTIVES}

CABG remains the best option and gold standard for most patients with multivessel and/or left main coronary artery disease. However, the results can always be improved. Intraoperative graft assessment with TTFM and HR-US is now recommended in current guidelines on myocardial revascularization and is a part of the "best practices" for coronary surgery just as multiple arterial revascularization and skeletonization of ITA are. A wider implementation of intraoperative graft assessment procedures would certainly contribute to improvement in graft patency and outcomes following myocardial revascularization. However, stronger evidence to support its use as "standard of care" during CABG procedures still requires further research. Large multicenter, randomized controlled trials and/or registry studies led by clinical investigators (nonindustry driven) are required to confirm the benefits of intraoperative graft assessment in order to improve the level of recommendation in clinical practice guidelines. Furthermore, intraoperative coronary assessment with FFR could become a "game changer", leading to new revascularization strategies based on functional and not anatomical assessment of coronary artery disease. The advantages and disadvantages of intraoperative graft assessment methods are listed in Table 3. 
Table 3. Advantages and disadvantages of intraoperative graft assessment

\begin{tabular}{|c|c|}
\hline Advantages & Disadvantages \\
\hline $\begin{array}{l}\text { - Lower possibility of graft dysfunction leading to improved outcomes } \\
\text { - Self-learning and self-improvement } \\
\text { - Better understanding of coronary graft physiology } \\
\text { - Confirmation of adequate flows in grafts and native vessels following intraoperative revision of grafts } \\
\text { to the surgical team with respect to early and late outcomes for the patient }\end{array}$ & $\begin{array}{l}\text { - There is a learning curve for the technical aspects of performing intraoperative graft assessment, } \\
\text { interpretation, and execution of the response } \\
\text { - Frequent (routine) use is required to develop the ability to interpret the findings judiciously, resulting in } \\
\text { appropriate decision-making } \\
\text { - Increase in operative time } \\
\text { - Graft revision can be frustrating and annoying for the surgeon, even though it is beneficial to the patient }\end{array}$ \\
\hline
\end{tabular}

\section{TAKE-HOME MESSAGE}

It is advisable to routinely perform intraoperative graft assessment for every graft and anastomosis during CABG surgery in order to confirm adequate graft function with respect to flows and morphology, respectively. It could potentially reduce perioperative myocardial ischemia or infarction, which could be detrimental to the patient's early and late outcomes. TTFM is a reliable, quick, and easy-to-perform intraoperative graft assessment technique that can verify adequate graft flows in most cases. Morphological evaluation of grafts and anastomoses with epicardial HR-US can be added to TTFM in order to improve the sensitivity and specificity and, thereby, the quality of graft assessment, which in turn enhances the quality, safety, and efficacy of CABG. Although revascularization strategies based on preoperative functional assessment of coronary artery disease hold promise, robust evidence in their favor for patients undergoing surgical revascularization is necessary and may drive the evolution of surgical revascularization in the future.

\section{DECLARATIONS}

Authors' contributions

Drafted and revised this manuscript: Marin-Cuartas M, Davierwala PM

\section{Availability of data and materials}

Not applicable.

\section{Financial support and sponsorship}

None.

\section{Conflicts of interest}

Both authors declared that there are no conflicts of interest. 


\section{Ethical approval and consent to participate}

Not applicable.

\section{Consent for publication}

Not applicable.

\section{Copyright}

(C) The Author(s) 2021.

\section{REFERENCES}

1. Alexander JH, Hafley G, Harrington RA, et al; PREVENT IV Investigators. Efficacy and safety of edifoligide, an E2F transcription factor decoy, for prevention of vein graft failure following coronary artery bypass graft surgery: PREVENT IV: a randomized controlled trial. JAMA 2005;294:2446-54. DOI PubMed

2. Kieser TM. Graft quality verification in coronary artery bypass graft surgery: how, when and why? Curr Opin Cardiol 2017;32:72236. DOI PubMed

3. National Institute for Health Care Excellence Evidence-based recommendations on MiraQ for assessing graft flow during coronary artery bypass graft surgery. Medical technologies guidance [MTG8]. Available from: https://www.nice.org.uk/guidance/mtg8. [Last accessed on 28 May 2021].

4. Neumann FJ, Sousa-Uva M, Ahlsson A, et al; ESC Scientific Document Group. 2018 ESC/EACTS Guidelines on myocardial revascularization. Eur Heart J 2019;40:87-165. DOI PubMed

5. Thuijs DJFM, Bekker MWA, Taggart DP, et al. Improving coronary artery bypass grafting: a systematic review and meta-analysis on the impact of adopting transit-time flow measurement. Eur J Cardiothorac Surg 2019;56:654-63. DOI PubMed PMC

6. Di Giammarco G, Marinelli D, Foschi M, Di Mauro M. Intraoperative graft verification in coronary surgery. J Cardiovasc Med (Hagerstown) 2017;18:295-304. DOI PubMed

7. Grondin CM, Castonguay YR, Lepage G, Meere C, Grondin P. Aortocoronary bypass grafts: early postoperative angiographic evaluation and reexploration for stenosis or thrombosis of the vein graft. Arch Surg 1971;103:535-8. DOI PubMed

8. Kieser TM, Taggart DP. The use of intraoperative graft assessment in guiding graft revision. Ann Cardiothorac Surg 2018;7:652-62. DOI PubMed PMC

9. Tan ES, Jessurun G, Deurholt W, et al. Differences between early, intermediate, and late angioplasty after coronary artery bypass grafting. Crit Pathw Cardiol 2008;7:239-44. DOI PubMed

10. Favaloro RG. Critical analysis of coronary artery bypass graft surgery: a 30-year journey. J Am Coll Cardiol 1998;31:1B-63B. DOI PubMed

11. Topol EJ, Nissen SE. Our preoccupation with coronary luminology: the dissociation between clinical and angiographic findings in ischemic heart disease. Circulation 1995;92:2333-42. DOI PubMed

12. Pijls NH, Fearon WF, Tonino PA, et al; FAME Study Investigators. Fractional flow reserve versus angiography for guiding percutaneous coronary intervention in patients with multivessel coronary artery disease: 2-year follow-up of the FAME (Fractional Flow Reserve Versus Angiography for Multivessel Evaluation) study. J Am Coll Cardiol 2010;56:177-84. DOI PubMed

13. Tonino PA, De Bruyne B, Pijls NH, et al; FAME Study Investigators. Fractional flow reserve versus angiography for guiding percutaneous coronary intervention. N Engl J Med 2009;360:213-24. DOI PubMed

14. Bruyne B, Pijls NH, Kalesan B, et al; FAME 2 Trial Investigators. Fractional flow reserve-guided PCI versus medical therapy in stable coronary disease. N Engl J Med 2012;367:991-1001. DOI PubMed

15. Toth GG, De Bruyne B, Kala P, et al. Graft patency after FFR-guided versus angiography-guided coronary artery bypass grafting: the GRAFFITI trial. EuroIntervention 2019;15:e999-1005. DOI PubMed

16. Glineur D, Grau JB, Etienne PY, et al. Impact of preoperative fractional flow reserve on arterial bypass graft anastomotic function: the IMPAG trial. Eur Heart J 2019;40:2421-8. DOI PubMed

17. Desai ND, Miwa S, Kodama D, et al. Improving the quality of coronary bypass surgery with intraoperative angiography: validation of a new technique. J Am Coll Cardiol 2005;46:1521-5. DOI PubMed

18. Rubens FD, Ruel M, Fremes SE. A new and simplified method for coronary and graft imaging during CABG. Heart Surg Forum 2002;5:141-4. PubMed

19. Ferguson TB Jr, Chen C, Babb JD, Efird JT, Daggubati R, Cahill JM. Fractional flow reserve-guided coronary artery bypass grafting: can intraoperative physiologic imaging guide decision making? J Thorac Cardiovasc Surg 2013;146:824-35.e1. DOI PubMed

20. Waseda K, Ako J, Hasegawa T, et al. Intraoperative fluorescence imaging system for on-site assessment of off-pump coronary artery bypass graft. JACC Cardiovasc Imaging 2009;2:604-12. DOI PubMed

21. Sahn DJ, Barratt-Boyes BG, Graham K, et al. Ultrasonic imaging of the coronary arteries in open-chest humans: evaluation of coronary atherosclerotic lesions during cardiac surgery. Circulation 1982;66:1034-44. DOI PubMed

22. Hiratzka LF, McPherson DD, Brandt B 3rd, Lamberth WC Jr, Marcus ML, Kerber RE. Intraoperative high-frequency epicardial echocardiography in coronary revascularization: locating deeply embedded coronary arteries. Ann Thorac Surg 1986;42:S9-11. DOI PubMed

23. McPherson DD, Armstrong M, Rose E, et al. High frequency epicardial echocardiography for coronary artery evaluation: in vitro and 
in vivo validation of arterial lumen and wall thickness measurements. J Am Coll Cardiol 1986;8:600-6. DOI PubMed

24. Haaverstad R, Vitale N, Tjomsland O, Tromsdal A, Torp H, Samstad SO. Intraoperative color Doppler ultrasound assessment of LIMA-to-LAD anastomoses in off-pump coronary artery bypass grafting. Ann Thorac Surg 2002;74:S1390-4. DOI PubMed

25. Di Giammarco G, Marinelli D. Intraoperative graft assessment and imaging of native coronary arteries. Indian J Thorac Cardiovasc Surg 2018;34:297-301. DOI PubMed PMC

26. Takami Y, Takagi Y. Roles of transit-time flow measurement for coronary artery bypass surgery. Thorac Cardiovasc Surg 2018:66:426-33. DOI PubMed

27. Laustsen J, Pedersen EM, Terp K, et al. Validation of a new transit time ultrasound flowmeter in man. Eur J Vasc Endovasc Surg 1996;12:91-6. DOI PubMed

28. Di Giammarco G, Pano M, Cirmeni S, Pelini P, Vitolla G, Di Mauro M. Predictive value of intraoperative transit-time flow measurement for short-term graft patency in coronary surgery. J Thorac Cardiovasc Surg 2006;132:468-74. DOI PubMed

29. Kim KB, Kang CH, Lim C. Prediction of graft flow impairment by intraoperative transit time flow measurement in off-pump coronary artery bypass using arterial grafts. Ann Thorac Surg 2005;80:594-8. DOI PubMed

30. Tokuda Y, Song MH, Ueda Y, Usui A, Akita T. Predicting early coronary artery bypass graft failure by intraoperative transit time flow measurement. Ann Thorac Surg 2007;84:1928-33. DOI PubMed

31. Jokinen JJ, Werkkala K, Vainikka T, Peräkylä T, Simpanen J, Ihlberg L. Clinical value of intra- operative transit-time flow measurement for coronary artery bypass grafting: a prospective angiography-controlled study. Eur J Cardiothorac Surg 2011;39:91823. DOI PubMed

32. Kieser TM, Rose S, Kowalewski R, Belenkie I. Transit-time flow predicts outcomes in coronary artery bypass graft patients: a series of 1000 consecutive arterial grafts. Eur J Cardiothorac Surg 2010;38:155-62. DOI PubMed

33. Di Giammarco G, Canosa C, Foschi M, et al. Intraoperative graft verification in coronary surgery: increased diagnostic accuracy adding high-resolution epicardial ultrasonography. Eur J Cardiothorac Surg 2014;45:e41-5. DOI PubMed

34. Taggart DP, Thuijs DJFM, Di Giammarco G, et al. Intraoperative transit-time flow measurement and high-frequency ultrasound assessment in coronary artery bypass grafting. J Thorac Cardiovasc Surg 2020;159:1283-92.e2. DOI PubMed

35. Gaudino M, Di Mauro M, Iacò AL, Canosa C, Vitolla G, Calafiore AM. Immediate flow reserve of Y thoracic artery grafts: an intraoperative flowmetric study. J Thorac Cardiovasc Surg 2003;126:1076-9. DOI PubMed

36. Noda M, Takami Y, Amano K, et al. Relation of fractional flow reserve with transit time coronary artery bypass graft flow measurement. Ann Thorac Surg 2021;111:134-40. DOI PubMed

37. D'Ancona G, Karamanoukian HL, Salerno TA, Schmid S, Bergsland J. Flow measurement in coronary surgery. Heart Surg Forum 1999;2:121-4. PubMed

38. Ferguson TB Jr, Chen C, Buch AN. Fractional flow reserve-guided coronary bypass surgery: should surgeons use it? Curr Opin Cardiol 2013;28:654-60. DOI PubMed

39. Fournier S, Toth GG, De Bruyne B, et al. Six-year follow-up of fractional flow reserve-guided versus angiography-guided coronary artery bypass graft surgery. Circ Cardiovasc Interv 2018;11:e06368. DOI PubMed

40. Shaw LJ, Berman DS, Maron DJ, et al; COURAGE Investigators. Optimal medical therapy with or without percutaneous coronary intervention to reduce ischemic burden: results from the Clinical Outcomes Utilizing Revascularization and Aggressive Drug Evaluation (COURAGE) trial nuclear substudy. Circulation 2008;117:1283-91. DOI PubMed

41. Sant'Anna FM, Silva EE, Batista LA, et al. Influence of routine assessment of fractional flow reserve on decision making during coronary interventions. Am J Cardiol 2007;99:504-8. DOI PubMed

42. Toth G, De Bruyne B, Casselman F, et al. Fractional flow reserve-guided versus angiography-guided coronary artery bypass graft surgery. Circulation 2013;128:1405-11. DOI PubMed

43. Alander JT, Kaartinen I, Laakso A, et al. A review of indocyanine green fluorescent imaging in surgery. Int J Biomed Imaging 2012;2012:940585. DOI PubMed PMC

44. Unno N, Suzuki M, Yamamoto N, et al. Indocyanine green fluorescence angiography for intraoperative assessment of blood flow: a feasibility study. Eur J Vasc Endovasc Surg 2008;35:205-7. DOI PubMed

45. Buda AJ, MacDonald IL, Anderson MH, Strauss HD, David TE, Berman ND. Long-term results following coronary bypass operation: importance of preoperative actors and complete revascularization. J Thorac Cardiovasc Surg 1981;82:383-90. PubMed 